\title{
Retained chest tube or tract artifact?
}

\author{
Anthony Coppolino, MD, ${ }^{\mathrm{a}}$ Elizabeth Yates, MD, ${ }^{\mathrm{b}}$ and M. Blair Marshall, MD ${ }^{\mathrm{a}}$
}

\footnotetext{
From the ${ }^{\mathrm{a}}$ Division of Thoracic Surgery and ${ }^{\mathrm{b}}$ Department of Surgery, Brigham and Women's Hospital, Harvard Medical School, Boston, Mass.

Disclosures: Authors have nothing to disclose with regard to commercial support.

Received for publication Aug 15, 2019; revisions received Aug 15, 2019; accepted for publication Aug 20, 2019; available ahead of print Nov 14, 2019.

Address for reprints: M. Blair Marshall, MD, Division of Thoracic Surgery, Department of Surgery, Brigham and

Women's Hospital, 75 Francis St, Boston, MA 02115 (E-mail: mmarshall16@bwh.harvard.edu).

J Thorac Cardiovasc Surg 2020;159:e247-8

$0022-5223 / \$ 36.00$

Copyright (C) 2019 Published by Elsevier Inc. on behalf of The American Association for Thoracic Surgery

https://doi.org/10.1016/j.jtcvs.2019.08.099
}

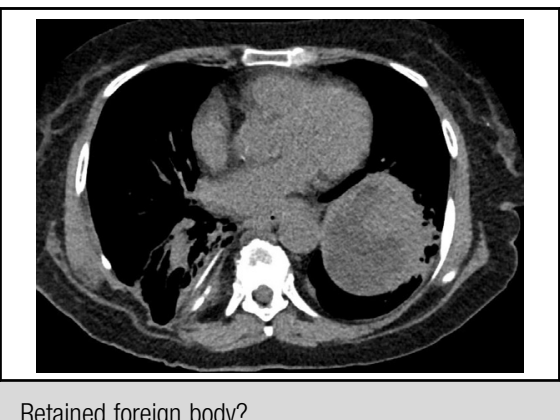

Retained foreign body?

Central Message

Drainage tracts can create calcified artifacts, appearing as retained foreign bodies.
A 70-year-old female patient with hypertension, prediabetes, IgA nephropathy, history of renal transplant, osteoporosis, stroke, and biliary sludge underwent an endoscopic ultrasound and retrograde cholangiopancreatography complicated by esophageal perforation. She underwent thoracotomy with primary repair. Eight months later, she was admitted for cholangitis. During her evaluation, she underwent a computed tomography scan of the abdomen. This was read as having a retained chest tube fragment (Figure 1, $A$ and $B$ ). Thoracic surgery was consulted. Review of chest radiographs from several months earlier, before tube removal and following tube removal (Figure 2, $A$ and $B$, respectively), proved that no tube fragment was left behind. The radiographic finding was an artifact from a calcified tube tract. The patient and primary teams were reassured and surgical intervention avoided. There is little published on calcification of drainage tracts. ${ }^{1}$ Increased awareness of this phenomenon may lead to decreased surgical intervention for mistaken foreign bodies.
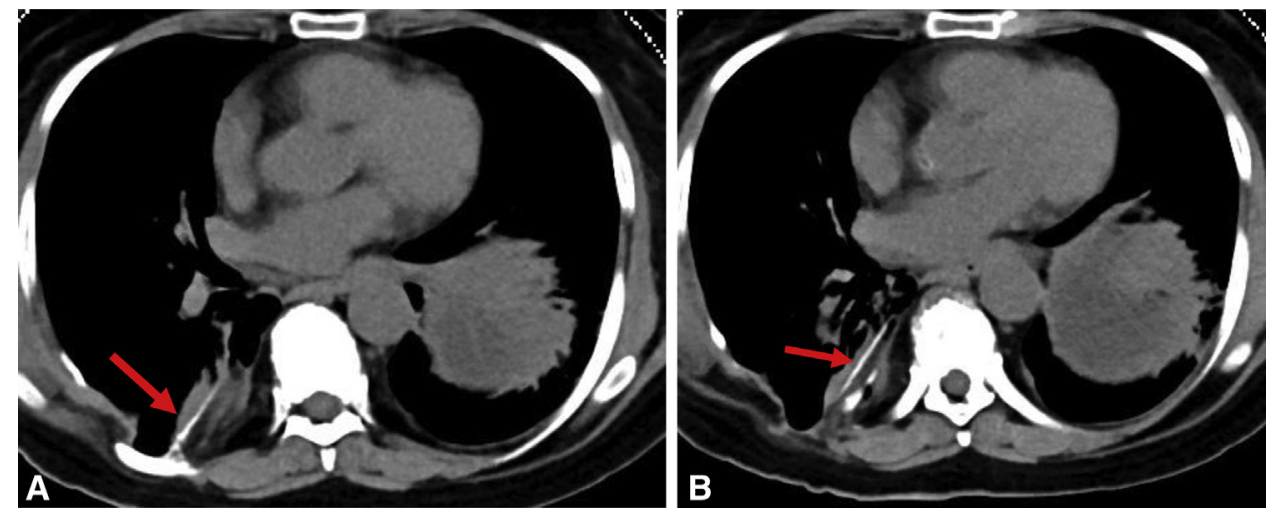

FIGURE 1. CT scan showing what appears to be a fragment of a retained foreign body in the posterior right hemothorax (red arrow). 



FIGURE 2. CT scan showing what appears to be a fragment of a retained foreign body in the posterior right hemothorax.

\section{Reference}

1. Lu A, Smith DC. Calcified fibrin sheath masquerading as retained catheter. $J$ Vasc Interv Radiol. 2013;24:691. 